\title{
Escritor-jornalista: o personagem conceitual como categoria de análise da obra de Graciliano Ramos
}

Hideide Brito Torres, Pós-Graduação em Estudos Literários, Universidade Federal de Juiz de Fora, Juiz de Fora, MG; E-mail: <hideide@gmail.com>.

\section{Resumo}

O artigo pretendeu discutir a maneira como Graciliano Ramos enxerga o ofício de jornalista a partir da construção de seus personagens em Angústia. Para contrapor nossa percepção, escolhemos a crônica 0 romance de Jorge Amado na qual elabora não só uma crítica literária a uma obra do escritor baiano, mas também da condição da literatura nos anos de 1930. Utilizamos o conceito de personagem conceitual, de Gattari e Deleuze, para refletir acerca de como os personagens de Angústia permitem adentrar à reflexão de Graciliano Ramos acerca do jornalista em seu contexto histórico. Trabalhamos a perspectiva da interdisciplinaridade a partir da ideia de zonas de confraternização, de Alfredo Pucheu, e de afetos, em Deleuze. Colocamos assim, em diálogo, ao menos três campos de saber: a literatura e o jornalismo, em presença da filosofia.

Palavras-chave: Personagem conceitual; Graciliano Ramos; Jornalismo; Literatura; Filosofia, Interdisciplinaridade

A partir do conceito de personagem conceitual, abordaremos a relação entre jornalismo e literatura em Graciliano Ramos, nas obras Angústia e O romance de Jorge Amado. Pretende-se tal análise na perspectiva do que Pucheu chama de zonas de confraternização, pelas quais

através de uma aventura da sensibilidade proporcionada pela intimidade maior com a vida do assunto pesquisado, buscando não sufocar metade de nossa vida emotiva e das nossas necessidades sentimentais e até de inteligência, se estuda tocando em nervos. Tocar a alma ou tocar em nervos é o que exige um ensaio poético, uma teoria literária e uma crítica poética contemporânea, que (...) tem o impacto do assunto turbinado, levando a plena força do sentido, provinda da potência vital, a atravessar, desde uma primeira instância, a alma, o coração ou os nervos do leitor (Pucheu, 2007: 11, grifos meus). 
Pelo fato de Ramos ter exercido a atividade jornalística, sua crítica e sua percepção deste profissional emergem de muito mais íntimo, na crônica e no romance, tocando em nervos da sociedade moderna, sob a ditadura militar, gerando uma forma de potência vital, que alcança com maior impacto o leitor. O autor traz para sua literatura a vitalidade da experiência, tornando singular a forma como constrói seus personagens.

Na crônica, Ramos tece sua apreciação ao livro de Amado, ao mesmo tempo em que traça seu panorama da literatura brasileira naquele momento histórico. Nela, "estão presentes elementos híbridos que expõem a capacidade de diálogo do escritor com seu tempo e seu público" (Santos, 2007: 3).

Já no romance, Graciliano Ramos constrói um personagem principal, Luiz Pereira da Silva e ao menos outros três (Pimentel, Moisés e Julião Tavares) que se veem como literatos/jornalistas. Soma-se a riqueza da psique do protagonista para desvelar a compreensão de Ramos acerca do que consiste a tarefa do jornalista e do escritor.

O romance entrelaça as instâncias de autor, narrador, personagem e leitor, fazendo do leitor cúmplice de Luís da Silva, ao saber seu terrível segredo: ter matado alguém e ainda estar impune.

Por meio do conceito de personagem conceitual, de Deleuze e Gattari, queremos perceber e analisar as relações que se constroem entre o escritor e o personagem. Pelas descrições que opera, as críticas que faz e pelos recursos literários em perspectiva crítica, Graciliano Ramos desenvolve a ação de escritor enquanto produtor, pois, segundo Benjamin,

Um autor que não ensina nada aos escritores não ensina nada a ninguém. Assim, é decisivo que a produção tenha um carácter de modelo, capaz de, em primeiro lugar, levar outros produtores à produção e, em segundo lugar, pôr à sua disposição um aparelho melhorado. (Benjamin, 2006: 271). 
De fato, esse romance inaugura uma nova modalidade de escrita no contexto daquele tempo, apesar de não receber tanto destaque na bibliografia do autor. Mas a prerrogativa de utilizar personagens-jornalistas conceituais na literatura não é original em Ramos. Ao tratar de Isaías Caminha (outro personagem jornalista), Bondan comenta: "nele e através dele pode o leitor contemplar boa parte da vida, das ilusões e das ideologias de Lima Barreto" (Bondan, 2002: 3). Enquanto os personagens se veem envolvidos em suas disputas em torno da vida mesma e, no seu interior, também do exercício de sua profissão, vão se desvelando não apenas práticas, mas também conceituações acerca do que é ser jornalista, notícia, ética, enfim, os valores e práticas sociais que geram e giram em torno do jornalismo.

O personagem conceitual designa a necessidade dos filósofos em utilizar personagens literários, fictícios ou históricos para expor seus próprios conceitos. Na perspectiva deleuziana, filosofia e literatura são instâncias não apenas de reflexão, mas de criação:

\footnotetext{
A filosofia - como a ciência, a arte, a literatura define-se, portanto, por seu poder criador ou, mais precisamente, pela exigência de criação de um novo pensamento (Machado, 2009: 14).
}

Entendemos, assim, que o conceito possa ser aplicado também aos escritores literários em busca de personagens por meio dos quais expressam discursos ou narram histórias, e também exercem uma função conceitual, fazem pensar, geram sentidos, criam.

\section{Jornalismo e literatura}

A relação entre jornalismo e literatura é percebida, em geral, como inegável. Seja quando se fala da presença de elementos jornalísticos em romances ou de elementos literários no discurso jornalístico - inclusive a existência de um gênero chamado "jornalismo literário" - seja quando se considera a narrativa jornalística e a narrativa literária no contexto da 
existência humana, há uma contaminação que não pode ser negligenciada (cf. Nicolato, 2006, p. 1). Assim já o definia Fernando Pessoa:

O jornalismo, sendo literatura, dirige-se todavia ao homem imediato e ao dia que passa. Tem a força directa das artes inferiores mas humanas, como o canto e a dança; tem a força de ambiente das artes visuais; tem a força mental da literatura, por de facto ser literatura. Como, porém, o seu fim não é senão ser literatura naquele dia, ou em poucos dias, ou, quando muito, numa breve época ou curta geração, vive perfeitamente conforme com os seus fins (Pessoa, 1998: 283, grifos meus).

A qualificação exposta por Pessoa não vem da qualidade do texto, mas da intenção do escritor. Trata-se de pensar o dia, não algo além. Na contemporaneidade, há uma aproximação entre jornalismo e literatura não apenas nos temas, mas também nos gêneros e recursos estilísticos. Por isso, a literatura dos séculos 20-21 pode abarcar tanto as preocupações mais individualistas e intimistas quanto trazer "o caráter mais objetivo e a urgência e o imediatismo da linguagem jornalística" (Nicolato, 2006: 2). O jornalismo, por sua vez, se apropria das técnicas e dos modos discursivos da literatura para produzir reportagens, perfis e biografias.

Para Santaella (apud Marques, 2009: 13) há também um momento histórico em que "a cultura vai perdendo a proeminência das belas letras e das belas artes para ser dominada pelos meios de comunicação". Ela entende esse momento como de "convergência", o que não significa "identificar-se, mas tomar rumos que, não obstante as diferenças, se dirijam para a ocupação de territórios comuns, nos quais as diferenças se roçam sem perder seus contornos próprios" (Santaella apud Marques, 2009: 13, grifos meus).

Apesar disso, ainda justifica-se estudar esta relação no interior dos estudos literários, haja vista que a conexão entre jornalismo e literatura não pode ser posta de lado.

O escritor-jornalista e o personagem conceitual 
Há um campo simbólico em torno do jornalismo: a ética, o mito da neutralidade e da objetividade, o compromisso com a verdade, por um lado; por outro, a manipulação do discurso, a habilidade em evidenciar ou esconder fatos, a relação escusa com setores da sociedade. Tais possibilidades de representação do jornalista circulam como potencializadoras de sentido. Esse "personagem" possui uma pretensa capacidade de dizer como as coisas funcionam, de dar ordem ao mundo e poder ao que fala.

Mas face a face com o jornalista enquanto autor, reconhecível pela análise de discurso do texto jornalístico, surge, por meio da literatura, outra construção do imaginário: o jornalista como personagem. Aí há que se analisar obras literárias que abordem o personagem-jornalista, nas quais o imaginário tem maior liberdade e meios criativos para se pronunciar.

Deve-se levar em conta a atividade jornalística desempenhada por Ramos e por outros escritores, como Lima Barreto ou Érico Veríssimo (que tem, inclusive, uma tribo jornalística, cf. Ritter, 2010) que transparece na constituição de suas obras e na construção de seus personagens conceituais.

"Os personagens conceituais (...) operam os movimentos que descrevem o plano de imanência do autor, e intervêm na própria criação de seus conceitos" (Deleuze e Gattari, 1992: 84).

Assim é que se pode observar a conexão entre Ramos e Luis da Silva, atestada por uma considerável fortuna crítica. Desta forma, o autor

é a idiossincrasia de seus personagens conceituais. E o destino do filósofo é de transformar-se em seu ou seus personagens conceituais, ao mesmo tempo que estes personagens se tornam, eles mesmos, coisa diferente do que são historicamente, mitologicamente ou comumente (o Sócrates de Platão, o Dioniso de Nietzsche, o Idiota de Cusa). O personagem conceitual é o devir ou o sujeito de uma filosofia, que vale para o filósofo (...). (Deleuse e Gattari, 1992: 85). 
O escritor-jornalista não apenas possui o jornalismo como profissão, mas é capaz de abstrair acerca dele e, utilizando-se da literatura como escopo criativo, conceituar, refletir e propor novas formas desse ofício, criticando-o de modo muito visceral. O texto literário se apropria das representações sociais e as transforma, por meio da verossimilhança, integrando-as ao ambiente ficcional. No caso de Graciliano Ramos, isso é percebido até com nuanças autobiográficas por alguns de seus analistas, algo por ele mesmo de vez em quando assumido e, volta e meia, negado. Um devir...

As obras no seu tempo: o escritor, o narrador e o cronista

Graciliano Ramos foi preso em 1936, em Maceió, durante o governo de Getúlio Vargas, acusado de participar da Intentona Comunista (1935). Naquele momento, sua datilógrafa havia acabado de entregar os manuscritos de Angústia para serem publicados. A esposa de Ramos levou o projeto adiante e só conseguiu chegar ao fim com o apoio de amigos, entre eles o também escritor José Lins do Rego. Logo em seguida, o escritor foi levado para o Rio de Janeiro, onde ficou preso até janeiro de 1937. Após sua libertação, ele foi morar em definitivo nessa capital e se dedicar mais especificamente à carreira de literato.

Luís Pereira da Silva, o narrador que fala em primeira pessoa em Angústia, é um funcionário público de 35 anos, que escreve artigos para jornais e elabora, a pedidos, críticas literárias e afins. Um sujeito solitário, de mau gosto com a vida. Ele se envolve com Marina, a qual é seduzida e engravida do antagonista, Julião Tavares. A narrativa mistura fatos do passado e do presente, o chamado fluxo de consciência (Humphrey, 1976). Ao final, desvela-se o motivo da enfermidade do autor, anunciada no primeiro parágrafo: o receio de ser pego pelo homicídio do opositor.

Luís fala acerca de sua percepção do ofício de escritor e de si mesmo como um mercenário da linguagem: 
Moisés e Pimentel apareciam às vezes, e alguns rapazes acanhados vinham pedir-me em segredo artigos e composições poéticas, que eu vendia a dez, a quinze mil-réis. Isto chegava para o aluguel da casa - e dr. Gouveia não me incomodava. (Ramos, s/d: 32).

Habitei-me a escrever, como já disse. Nunca estudei, sou um ignorante e julgo que meus escritos não prestam. Mas adquiri cedo o vício de ler romances e posso, com facilidade, arranjar um artigo, talvez um conto. (...) (Ramos, s/d: 45).

Em Angústia, aparece o desprezo pela profissão exercida em subserviência, sendo que o autor-narrador frequentemente compara-se a um rato ou cachorro. Já na crônica, escrita em 17 de fevereiro de 1935, Ramos afirma:

Há uma literatura antipática e insincera que só usa expressões corretas, só se ocupa de coisas agradáveis, não se molha em dia de inverno e por isso ignora que há pessoas que não podem comprar capas de borracha (Ramos, 1962: 94).

O literário dialoga com a realidade dura, expondo a crueza do fazer motivado pela questão econômica, crítica social contundente, que ressoa em seu personagem no romance. Luis admite:

A minha linguagem é baixa, acanalhada. Às vezes sapeco palavrões obscenos. Não os adoto escrevendo por falta de hábito e porque os jornais não publicariam, mas é minha maneira ordinária de falar quando não estou na presença dos meus chefes. (Ramos, s/d: 49)

E se Luís evita os palavrões, Julião Tavares possui uma linguagem rebuscada:

O outro sujeito inútil que nos apareceu era muito diferente. Gordo, bem vestido, perfumado e falador, tão falador que ficávamos enjoados com as lorotas dele. Não podíamos ser amigos. Em primeiro lugar, o homem era bacharel, o que nos distanciava. (...) Além disso, Julião Tavares tinha educação diferente da nossa. Vestia casaca, frequentava os bailes da Associação Comercial e era amável em demasia. (Ramos, s/d: 48).

Dizia, referindo-se a um poeta morto: - Era um grande espírito, um nobre espírito. Quanta emoção! Além disso conhecimento perfeito da língua. Artista privilegiado. Filho de uma puta. (...) Não podia ser nosso amigo. (Ramos, s/d: 49). 
$\mathrm{Na}$ crônica, Graciliano assume a veemência de seu personagem:

Essa literatura é exercida por cidadãos gordos, banqueiros, acionistas, comerciantes, proprietários, indivíduos que não acham que os outros tenham motivo para estar descontentes. (Ramos, 1962: 94).

Alfredo Pucheu, ao abordar a crítica literária, afirma ser possível encontrar aquela que instiga o leitor, desperta-lhe paixões e vai além de seu objetivo inicial. Ela

não é apenas um meio para atingirem uma lucidez maior da obra poética paralela a ela, mas que ela já é, nela mesma, poema, escrita, criação de arranjos animadores do pensamento. Ao invés de um paralelismo entre crítica e poesia, uma encruzilhada, com bifurcações abrindo-se em desdobramentos. Ao invés de uma hierarquização entre uma prática menor e uma maior, uma simultaneidade de forças correlatas, que se transpassam e se autonomizam. (Pucheu, 2007: 21)

A relação entre a crônica de Ramos e seu romance aponta como o ofício de jornalista e de literato o impelia a verificar a si mesmo e aos seus contemporâneos como produtores sociais. A crítica na crônica esbarra em si mesmo. Junto ao romance são essa "simultaneidade de forças correlatas" e explodem ambas em um processo criativo, no qual não pode hierarquizar, por fim. Encontram-se na encruzilhada criativa que permite a Graciliano pensar o fazer jornalístico num momento em que se exige a aproximação ao nacional, ao povo e seu linguajar (o advento do modernismo). E que também os artistas estão sob o crivo ferrenho e constante da ditadura.

Em depoimento a Homero Senna, em 1948, Ramos fala: "Nunca pude sair de mim mesmo. Só posso escrever o que sou. E, se as personagens se comportam de modos diferentes, é porque não sou um só". No caso de Luís, de Angústia, a quantidade de afazeres ao mesmo tempo, a variedade de pequenos trabalhos, a luta para a sobrevivência financeira e a pressão social em torno da revolução encontram ecos na realidade do autor. 
Assim como os seus leitores, Graciliano Ramos vivera as mazelas de uma vida longe dos literatos, como afirma: "Nunca fui literato, até pouco tempo vivia na roça e negociava. Por infelicidade, virei prefeito no interior de Alagoas e escrevi uns relatórios que me desgraçaram" (trecho de carta enviada por Graciliano a Raúl Navarro, tradutor argentino, em 1937). Talvez daí venha sua aspereza com aqueles que ignoram as mazelas de seus contemporâneos. Ele critica, na crônica, o afastamento entre a literatura e o público nos seguintes termos:

Ora, não é verdade que tudo vá assim tão bem. Umas
coisas vão admiravelmente, porque há literatos com
ordenados razoáveis; outras vão mal, porque os
vagabundos que dormem nos bancos dos passeios não
são literatos nem capitalistas. Nos algodoais e nos
canaviais no Nordeste, nas plantações de cacau e de
café, nas cidadezinhas decadentes do interior, nas
fábricas, nas casas de cômodos, nos prostíbulos, há
milhões de criaturas que andam aperreadas. (Ramos,
1962: 95, grifos meus) A partir daí, Ramos procura demonstrar as diferenças entre esses pretensos literatos e o romance de Amado. Ele apresenta como argumentos favoráveis a aproximação da linguagem literária com a fala do povo e traz à tona quase que a mesma expressão de Luís no romance:

Os escritores atuais foram estudar o subúrbio, a fábrica, o engenho, a prisão da roça, o colégio do professor cambembe. Para isso resignaram-se a abandonar 0 asfalto e o café, viram de perto muita porcaria, tiveram a coragem de falar errado, como toda gente, sem dicionário, sem gramática, sem manual de retórica. Ouviram gritos, pragas, palavrões e meteram tudo nos livros que escreveram. Podiam ter mudado os gritos em suspiros, as pragas em orações. Podiam, mas acharam melhor pôr os pontos nos ii. (Ramos, 1962: 95).

E aqui ressurgem os sonhos do frustrado Luís da Silva em produzir um romance que fizesse a diferença, em assumir os palavrões enclausurados pela economia, a política e até a sociabilidade, que, escondidos, fazem morrer a indignação criativa que deveria caracterizar o ofício do jornalista.

Se em Angústia, Luís da Silva "não achava certo era ouvir Julião Tavares todos os dias afirmar, em linguagem pulha, que 
- Brasil é um mundo, os poetas alagoanos uns poetas enormes..." (Ramos, s/d, p. 50), é Graciliano que, na crônica, reverbera contra a literatura que "acha que tudo está direito, que o Brasil é um mundo e que somos felizes. Está claro que ela não sabe em que consiste essa felicidade, mas contenta-se com afirmações e ufana-se do seu país" (Ramos, 1962: 94).

Por sua vez, os jornais prestam um desserviço, desinformam e deformam o leitor:

\begin{abstract}
Escreva um artigo a respeito de salários, seu Luís. Bocejo e sapeco uma literatura ordinária, constrangido. Sei que estou praticando safadeza. Penso no que acontecerá depois. Quando houver uma reviravolta, utilizarão minhas habilidades de escrevedor? (Ramos, s/d: 158).
\end{abstract}

A dependência econômica de seu empregador, do jornal e dos contos e poesias vendidos avulsamente angustia 0 personagem-jornalista: "Eles escrevem assim porque receberam ordem para escrever assim. Depois escreverão de outra forma. É tapeação, é safadeza” (Ramos, s/d: 157). O ofício anula a pessoa: "Seu Luís arrumava no papel as ideias e os interesses dos outros. Que miséria" (Ramos, s/d: 142).

O que move Luís é o jeito mais rápido de fazer lucro: ele escreve resenhas superficiais dos livros que recebe pelo correio e depois os vende ao sebo. Quando alguém Ihe pede opinião sobre um autor desconhecido, afirma ser ruim para poupar trabalho.

É interessante a passagem na qual Luís da Silva descreve seu projeto megalomaníaco, sempre de novo sufocado. Ele está nu, no banheiro da casa. Sentado, de pernas estiradas, "dão-se grandes revoluções na minha vida" (Ramos, s/d: 132). Nessa posição, Luís visualiza os jornais posicionando-se contra e a favor de sua obra-prima. O diretor sente ciúmes de seu sucesso. E, é claro, a aprovação dos críticos: "Meus parabéns, seu Silva. O senhor escreveu uma obra excelente. Está aqui a opinião dos críticos" (Ramos, s/d: 132). 
Ao abordar a escrita de Jorge Amado, Graciliano, o crítico, volta a afirmar que é perigoso a um romancista aproximar-se da verdade, sob o risco de ser acusado de falta de imaginação. Percebe que a investigação feita por Amado dá à obra Suor um caráter de reportagem. E volta a enfatizar a miséria humana, que se expressa mais habilmente na ingenuidade do que na fala politizada de alguns personagens do livro e que circulava pelas ruas. Ramos usa como exemplo na crônica uma situação que também aparece em Angústia:

Chega um desses homens, traduz a fala em linguagem política, de cartaz - e sentimos um pouco mais ou menos o que experimentamos quando vemos letras explicativas por baixo de desenhos traçados a carvão nas paredes (Ramos, 1962: 27).

No romance, quando Luís segue Marina ao local onde esta faz um aborto, ele se depara com a frase Proletários uni vos. Assim, sem vírgula e sem traço. No bairro periférico, sujo, era preciso que o pensamento revoltoso fosse revestido da linguagem apropriada para ser levado a sério:

Aquela maneira de escrever comendo os sinais indignoume. Não dispenso as vírgulas e os traços. Quereriam fazer uma revolução sem vírgulas e sem traços? Numa revolução de tal ordem não havia lugar para mim. Mas então? Um homem sapeca as pestanas, colabora nos jornais e isso não vale nada? Pois sim. É só pegar um carvão e sujar a parede. (Ramos, s/d: 164-165)

Mesmo quando o personagem se torna antipático, segue a demonstrar a forma pela qual o ofício do jornalista, em particular do crítico literário nesse caso, deveria ser desempenhado. A literatura e a sociedade estão distanciados por conta dessa prática. É tanto fato que Luís da Silva, em meio aos pobres que bebericam num bar, pensava em "coisas sagradas. Deus, pátria, família, coisas distantes" (Ramos, s/d, p. 168) e a seguir desejou "retirar-(se) dali, ingressar de novo na sociedade dos funcionários e dos literatos" (Ramos, s/d, p. 168).

O elogio último de Graciliano a Jorge Amado na crônica reside no fato de conseguir enxergar a presença do autor no texto: 
Em Suor há um personagem de carne e osso muito mais importante que os outros: é Jorge Amado, que morou na Ladeira do Pelourinho, 68 e lá conheceu Maria Cabassu e todos aqueles seres estragados que the forneceram material para um excelente romance (Ramos, 1962: 98).

Talvez seja essa a razão principal do fracasso de Luís da Silva como escritor e como jornalista. O que ele faz no exercício de sua profissão é usar palavras de outros, é descentrar-se e desaparecer num discurso que não lhe é seu, o que é similar ao que ocorre com Pimentel, Moisés e Julião Tavares, cada um de uma forma.

Considerando o momento histórico tenso, os personagens de Angústia são o retrato de uma crise do indíviduo, sim, mas também do jornal enquanto instituição. Afinal - detalhe semiótico irônico - jornal e o livro estão nas mãos de todos os personagens o tempo todo, mas eles nunca extraem desses objetos a capacidade de mudar sua situação. São instrumentos a serviço da alienação, da distração e da manutenção do status quo. A um leitor minimamente atento, como diria Pucheu, dá mesmo nos nervos, afeta e potencializa a reflexão, fazendo surgir um novo pensar.

\section{Considerações finais}

Angústia começa exatamente com a descrição do esvaziamento do narrador. Corpo que não sente, olhos que não veem, dedos sem noção de si. Impotência é a palavra que descreve bem tal estado. O confronto dessa obra e da crônica com o pensamento de Graciliano, por sua vez, gera uma potência, derivada, justamente dessa aventura do sensível (Pucheu, 2007: 11), da habilidade do autor em amarrar as experiências de sua escrita como jornalista, crítico e romancista numa linguagem que chega para afetar o leitor.

Para Ramos, a atividade jornalística e literária encontra-se enclausurada pelos interesses políticos e econômicos, diminuindo a potência do ser, inferiorizando-o à condição animal. Na crônica, a crítica aparece de modo mais diretivo e claro, o que evidencia Luís da Silva como personagem 
conceitual, e permite acessar o pensamento e a reflexão do autor sobre o modo de ser e de estar do jornalista no mundo.

\section{Referências Bibliográficas}

ARAÚJO, B. (2012). A narrativa jornalística e a construção do real. BOCC. Beira Interior: Universidade da Beira Interior. Retrieved from http://www.bocc.ubi.pt/pag/araujo-bruno-a-narrativa-jornalisticaconstrucao-real.pdf.

BENJAMIN, Walter (2006). O autor como produtor. In $A$ modernidade. Obras escolhidas de Walter Benjamin. Lisboa: Assírio \& Alvim, p. 271-293.

BONDAN, Marcos (s/d). Recordações do Escrivão Isaías Caminha Resumo Biblioteca Virtual. Retrieved from http:/ www.bondan.pro.br/biblioteca/isaias.htm.

DELEUZE / SPINOZA (s/d). Le Cour de Gilles Deleuze. Cours Vincennes. 24/01/1978. Retrieved from http://www.webdeleuze.com/php/texte.php?cle=194\&groupe=Spinoza \&langue $=5$.

DELEUZE, Gilles e GUATTARI, Felix (1992). O que é filosofia. Rio de Janeiro, RJ: Editora 34.

DELEUZE, Gilles (1992). Conversações. São Paulo, SP: Editora 34. HUMPHREY, R (1976). Fluxo de consciência. São Paulo, SP: McGraw-Hill.

MACHADO, Roberto (2009). Deleuze, a Arte e a Filosofia. Rio de Janeiro, RJ: Zahar.

MARQUES, Fabrício (2009). Jornalismo e literatura: modos de dizer. In Conexão Comunicação e Cultura. Caxias do Sul, RS: UCS, v. 8, n. 16, p. 11-27. Retrieved from: http://www.ucs.br/etc/revistas/index.php/conexao/article/viewFile/124/115 MOTTA, Luiz Gonzaga (2004). Jornalismo e configuração narrativa da história do presente. In Compós. São Paulo, SP: Compós. Retrieved from http://www.compos.org.br/e-compos.

NICOLATO, R. (2006). Jornalismo e Literatura: aproximações e fronteiras. In Congresso Brasileiro De Ciências Da Comunicação, n. 29, 2006, Brasília. Anais... São Paulo, SP: Intercom. CD-ROM 
PESSOA, Fernando (1972). Obras em prosa. Rio de Janeiro, RJ: Aguilar.

PESSOA, Fernando (1998). Ideias estéticas: obras em prosa. Rio de Janeiro, RJ: Nova Aguilar.

PUCHEU, Alberto (2007). Pelo colorido, além do cinzento. Rio de Janeiro, RJ: Beco do Azougue.

RAMOS, Graciliano (s/d). Angústia. Rio de Janeiro, RJ: Record.

RAMOS, Graciliano (1962). O romance de Jorge Amado. In RAMOS, Graciliano. Linhas Tortas. Rio de Janeiro, RJ: Record.

RITTER, Eduardo (2010). Jornalismo e literatura: a tribo jornalística de Erico Verissimo. Porto Alegre, RS: PUCRS, 2010 (Dissertação. Orientação de Hohlfeldt, Antônio Carlos).

ROLNIK, Suely (2006). Cartografia sentimental: transformações contemporâneas do desejo. Porto Alegre, RS: Ed. UFRGS.

SANTAELLA, Lúcia (1992). Cultura das Mídias. São Paulo: Razão Social, 1992.

SANTOS, Regina Maria dos (2007). Jornalismo e atividade literária: a escrita cotidiana da história no jornal. In Anais Associação Nacional de História - ANPUH, XXIV Simpósio Nacional de História, p. 1-8. Retrieved from http://anpuh.org/anais/wpcontent/uploads/mp/pdf/ANPUH.S24.0620.pdf. 